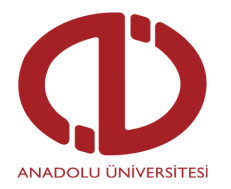

Açıköğretim Uygulamaları ve Araştırmaları Dergisi AUAd

https://dergipark.org.tr/tr/pub/auad

Gönderim: 17.01.2021

Düzeltme: 17.03 .2021

Kabul: 10.04.2021

Tür: Araştırma Makalesi

\title{
Mutlu çevrimiçi okul
}

\author{
Mustafa FIDAN ${ }^{\mathrm{a}}$ \\ aAnkara Özel Acar Okulları, ORCID: 0000-0002-2900-7631
}

\begin{abstract}
Özet
COVID-19 sırasında okulların aniden kapanması, birçok okulu bileşenlerinin mutluluğu konusunda belirsiz bıraktı. Bu çalışma, uzaktan öğretim gerçekleştirilen ilköğretim okullarında mutlu çevrimiçi okul olgusunu sorgulamaktadır. Bu çalışmanın amacı, mutlu çevrimiçi okulu öğrenci, veli ve öğretmen görüşleri doğrultusunda ortaya koymaktır. Bu nitel araştırma olgu bilim desenindedir. Araştırmanın çalışma grubunu oluşturan 56 öğrenci, 32 veli ve 17 öğretmen ile yarı-yapılandırılmış görüşme yöntemi kullanılarak veriler toplanmıştır. Görüşme soruları ilgili alan yazına dayalı olarak geliştirilmiş ve katılımcılardan derinlemesine bilgi toplamak için kullanılmıştır. Çalışma verileri içerik analizi yöntemiyle çözümlenmiştir. Araştırma bulgularına dayalı olarak, öğrenci, veli ve öğretmen mutluluklarının birleşiminde mutlu çevrimiçi okul açıklanmıştır. Öğrencilere göre mutlu çevrimiçi okul, eğlence, kolaylık, özgürlük ve esnekliktir. Velilere göre mutlu çevrimiçi okul, şeffaflık, sağlık, güvenlik, esneklik ve ekonomikliktir. Öğretmenlere göre mutlu çevrimiçi okul, sağlık, kolaylık, inovasyon ve zamandır. Mutlu çevrimiçi okul öğrenci, veli ve öğretmenler için öznel anlamlandırılmış gibi gözükse de, her bir bileşenin mutluluğu okulun toplam mutluluğuna katkı sunmaktadır.
\end{abstract}

Anahtar Sözcükler: Mutluluk, Mutlu Okul, Çevrimiçi Eğitim, Covid-19

\section{Happy Online School}

\begin{abstract}
The sudden closure of schools during COVID-19 has left many schools uncertain about their component's happiness. Participants in this study were compelled to engage in online education. The aim of this study is to present the happy online school according to the opinions of students, parents and teachers. This qualitative research is in phenomenology design. The study group of the research consists of 56 students, 32 parents and 17 teachers. Data were collected using the semi-structured interview method and analyzed using content analysis. According to students, happy online school is fun, convenience, freedom and flexibility. According to parents, happy online school is transparency, health, safety, flexibility and affordability. According to teachers, happy online school is health, convenience, innovation and time. According to the results of the study, a happy online school is the sum of the opinions of students, teachers and parents. Although happy online school seems to be subjectively meaningful for students, parents and teachers, the happiness of each component contributes to the total happiness of the school.
\end{abstract}

Keywords: Happiness, Happy School, Online Education, Covid-19 


\section{Giriş}

İnternet kuşkusuz hayatın her alanını derinden etkilemektedir. Covid 19 pandemisi ile ortaya çıkan değişim fırtınasında internete karşı olası kuşkular da görünür değildir. Fırtına dindiğinde manzaranın nasıl görüneceği net olmasa da hiçbir şeyin eskisi gibi olmayacağı öngörülmektedir. Okulların içinde bulunduğu manzarada, genel öngörüler çerçevesinde yeni normale uygun çözümler arandığı söylenebilir. Bazı okulların bu süreci avantaja çevirdiği bazılarının ise süreci iyi yönetemediği ifade edilmekteyse de iyi veya kötü her durumda internet üzerinde oluşturulan çevrimiçi okul, pandemi fırtınasından eğitimi bir ölçüde kurtarmayı başarmaktadır.

Geleneksel okulların sosyal mesafe gerekçesi ile yasaklandığı gerçeklikte internet üzerinden oluşturulan acil çevrimiçi okul zorunluluktan doğan bir kurtarıcıdır. Pandemi koşullarında gündeme gelen sosyal mesafe, bir aşının, tedavinin veya her ikisinin de geliştirilmesini beklerken en etkili önleyici strateji olarak kabul edildiğinden, çevrimiçi okulun acil ve zorunlu bir kurtarıcı olduğu söylenebilir. Dolayısıyla geride bıraktığımız bir yıla yakın sürede birçok okulun acilen ve zorunlu olarak çevrimiçi okula dönüştüğü görülmektedir (Rose, 2020).

Çevrimiçi okul, öğrenciler, ebeveynler ve öğretmenler arasında işbirliğine dayalı bir topluluk çabası olarak tanımlanmaktadır (Aliyyah ve ark., 2020). Çevrimiçi okul, internet aracılığıyla inovatif öğrenme ortamları sunmaktadır. Çevrimiçi okulda öğrencilerin öğrenme kaynaklarına erişiminin sağlanması, öğrenciler ile öğretmen arasında iletişimin kolaylaştırılması, işbirliğine dayalı çalışmaların yapılması ve daha fazlası için idari desteğin sağlandığı sanal olanaklar söz konusudur (Volery ve Lord, 2000). Çevrimiçi okulun soyağacı ise karmaşıktır. Çevrimiçi okul bir yandan eğitim teknolojisi ve bilgisayar destekli eğitimin doğrudan soyundan gelmekte; öte yandan uzaktan eğitim ile ortak bir geçmişi bulunmaktadır (Larreamendy-Joerns ve Leinhardt, 2006).

Uzaktan eğitim, eğitim teknolojileri ve bilgisayar destekli eğitim yazınları (Bates ve Bates, 2005; Brusilovsky ve ark., 1998; Firat ve ark., 2018; Moore, ve Kearsley, 1996; Roblyerz ve Doering, 2006) pandeminin ilk döneminde çevrimiçi okulu anlama ve uygulamada yardım sağlamıştır. Pandemi döneminde mevcut çevrimiçi eğitim tartışmaları (Bozkurt ve Sharma, 2020; Dwivedi ve ark., 2020; Hodges ve ark., 2020; Keskin ve Kaya, 2020; Iivari ve ark., 2020; Rose, 2020; Telli Yamamoto ve Altun, 2020) ise çevrimiçi okul hakkında yaşantı ürünü bilgi sağlamada ve kavramsal olarak ele alınması gereken konuları önermede yardımcı olmaktadır. Ayrıca mevcut güncel çalışma sonuçları, çevrimiçi okulun geçici bir çözüm olmanın ötesinde kalıcı hale gelmekte olduğuna işaret etmektedir. 
Yamamoto ve Altun (2020) tarafından yapılan çalışma sonuçlarına göre, yakın gelecekte çevrimiçi okulların, ikincil bir alternatif ya da yüz yüze öğrenmede destek fonksiyonu olmak yerine, eğitimin asli zemini haline dönüşeceği öngörülmektedir. Benzer şekilde Keskin ve Kaya (2020) tarafından yapılan çalışma sonuçlarında pandemi sürecinde yüz yüze eğitime alternatif bir çözüm olarak değerlendirilen çevrimiçi okulun yakın gelecekte daha çok kullanılabileceği öngörülmektedir. Bir diğer çalışmada ise derin pandemi etkilerinin, gelecekteki eğitim alma şeklini sonsuza kadar değiştirebileceği belirtilmektedir (Rose, 2020). Dolayısıyla eşi benzeri görülmemiş pandemi dönemiyle birlikte, çevrimiçi okulun kalıcı bir eğitim bileşeni olacağı söylenebilir.

Eğitiminde inovatif bir olgu olarak çevrimiçi okul gerçeğini sorgulayan çalışmalar yapılmaktadır (Barton, 2020; Burns ve Gottschalk, 2020; Daniel, 2020; Fidan, 2020b; Hebebci ve ark., 2020; Telli Yamamoto ve Altun, 2020). Bu çalışmalarda genel olarak çevrimiçi okul uygulamalarının olumsuz yönlerinin ön planda olduğu görülmektedir. Barton (2020) tarafindan yapılan çalışmada pandemi sürecindeki zorunlu çevrimiçi eğitimin öğrenci, öğretmen ve velilere yüksek oranda zorluklar getirdiği öne çıkarılmaktadır. Fidan (2020b) tarafından yapılan çalışmaya katılan öğretmenler, olumsuz yönleri daha çok yer verirken aynı zamanda olumlu yönleri ifade ederken "hiç değilse, en azından" gibi ifadeler kullanmaktadırlar. Bir diğer çalışmada ise "olağanüstü koşullarda dahi eğitimin planlı ve programlı bir şekilde yürütülebilmesi” olumlu yön olarak ifade edilmektedir (Hebebci ve ark., 2020).

Çevrimiçi okulun olağanüstü koşullarda dahi eğitimin yürütülebilmesinden öte bir olgu olduğu düşünülmektedir. Sadece pandemi koşullarında değil pandemi sonrasında da çevrimiçi okulun yaşamaya devam edeceği öngörülmektedir. Bu kapsamda çevrimiçi okulu sadece pandemi ile birlikte değerlendirme ve olumsuz yönlerine odaklanmanın bir hata olduğu bu çalışmanın temel çıkış noktasıdır. Araştırmacı bu çalışmayla çevrimiçi okuldaki yönetsel inovasyonu keşfetme (Fidan, 2018) ve sürecin olumlu yönlerini öne çıkarma amacındadır. Bu amaçla çevrimiçi okulun mutlu yönlerine odaklanılmaktadır. Çünkü mutluluk eğitim adına yapılan her şeyi ölçüsüne vurabileceğimiz bir mihenk taşıdır (Noddings, 2006). Eğitimin bugünü ve geleceğinde söz sahibi olacağı düşünülen çevrimiçi okulun (Rose, 2020) mutluluk bileşenlerinin belirlenmesi alan yazına katkı sunabilecektir.

Mutluluk, üzerinde ortak bir kabulün bulunmadığı, öznel anlamlar yüklenen özel bir kavramdır (Griffin, 2007). Burada mutluluğa yüklenen öznel anlamlar çevrimiçi mutlu okulu açıklama amacıyla araştırılmaktadır. Öte yandan bazı kaynaklarda mutluluk, kısa ve kalıcı mutluluk olmak üzere ikiye ayrılmaktadır (Jacobsen, 2007). Çalışma ile ortaya çıkarılması planlanan kısa mutluluk örnekleri, çevrimiçi okul bağlamında kalıcı mutlulukları keşfetmede 
kullanılabilir. Bir diğer yönüyle mutluluk, kişinin sürdürmekte olduğu hayatı ne kadar sevdiğiyle ilişkilidir (Veenhoven, 2005). Bu çalışma ile çevrimiçi okulun sevilen yönleri ortaya çıkarılmaktadır.

Çevrimiçi okul ve mutluluk kavramlarını birlikte araştırdığımızda karşımıza çoğunlukla mutsuzluk ve çok sevilesi olmayan çalışma sonuçları çıkmaktadır. Örneğin, çevrimiçi eğitimde, ebeveynler için ruh sağlığının kötüleşmesi, çocukların davranış sağlı̆̆ının kötüleşmesi ve düzenli çocuk bakımı kaybı gibi nedenlerle mutsuzluk oranlarında yükseklik görüldüğü belirtilmektedir (Patrick ve ark., 2020). Benzer şekilde, birçok ailenin, iş kaybı, gelir kaybı, bakım yükü ve hastalık dahil olmak üzere zorluklarla mücadele etmek zorunda kalması hem ailenin hem de çocukların mutluluğunu olumsuz etkilemektedir (Gassman-Pines ve ark., 2020).

Fidan (2020b) tarafindan yapılan çalışmada ise, bütün olumsuzluklara rağmen çocukların eğitimden kopmamaları ve sosyal çevre ile ilişkinin devam ediyor olması çevrimiçi eğitimin olumlu yönü olarak belirtilmektedir. Bu çalışmaya göre bütün mutsuzluk ihtimallerine rağmen öğretmenler öğrencileri ile eğitime devam etmekten mutludurlar. Sharif ve diğerleri (2020) tarafından yapılan çalışmada çevrimiçi okulun avantajlarına odaklanma, yeniliği benimseme ve sürece liderlik etme önerilmektedir. Ayrıca alan yazında çevrimiçi okulların sadece akademik amaçlar için ortaya çıkmadığı ifade edilmektedir. Dijital çağ ve pandemi koşullarında çevrimiçi okulların temel amaçları arasında sağlıklı ve mutlu çocuklar yetiştirmek önemle vurgulanmaktadır (Burns ve Gottschalk, 2020).

\section{Araştırma Sorunsalı}

$\mathrm{Bu}$ çalışmanın amacı, çevrimiçi okulda öğrenciyi, öğretmeni ve veliyi mutlu eden yönlerin ortaya çıkarılmasıdır. Bu kapsamda araştırmada aşağıdaki sorulara yanıt aranmıştır:

1. Çevrimiçi eğitimde öğrencileri neler mutlu etmektedir?

2. Çevrimiçi eğitimde velileri neler mutlu etmektedir?

3. Çevrimiçi eğitimde öğretmenleri neler mutlu etmektedir? 


\section{Yöntem}

\section{Araștırma Modeli}

$\mathrm{Bu}$ nitel araştırma olgu bilim (fenomenoloji) desenindedir. Olgu bilim deseni, bir olgu hakkında yaşanmış deneyimleri ortaya çıkaran bir çalışma yöntemidir (Creswell ve Poth, 2016). Öğrenci, veli ve öğretmen deneyimlerinde mutlu çevrimiçi okul olgusunu araştıran bu çalışma olgu bilim deseni için uygundur (Yıldırım ve Şimşek, 2003). Olgu bilim desenindeki bu araştırma çevrimiçi mutlu okula ilişkin katılımcıların farklı bakış açılarına odaklanmıştır (Moustakas, 1994).

\section{Araştırma Alanı ve Katılımcılar}

Araştırmanın çalışma grubu amaçlı örnekleme yöntemi ile belirlenmiştir. Amaçlı örnekleme yöntemi ile araştırma problemine uygun katılımcılara ulaşılabilmek mümkündür (Creswell ve Poth, 2016). Bu araştırmada çevrimiçi okulu deneyimleyen katılımcılara ulaşılmak istenmiştir. Bu amaçla, Ankara ili Yenimahalle ilçesinde 2019-2020 öğretim yılı bahar döneminde acil uzaktan öğretim gerçekleştiren okullarda araştırma yürütülmüştür. Eğitimi tümüyle çevrimiçine taşıyan okullarda, pandeminin başlangıcından itibaren çevrimiçi eğitimi yaşayan, 56 öğrenci, 32 veli ve 17 öğretmen ile görüşmeler yapılmıştır. Olgu bilim yöntemi olguyu yaşayan ve yaşadıklarını görüşmeye yansıtabilecek katılımcılar ile yürütülmektedir (Yıldırım ve Şimşek, 2003). Dolayısıyla mutlu çevrimiçi okulu yaşayan ve çevrimiçi süreçlerdeki mutlu yaşantılarını yansıtabilecek uygun katılımcılara ulaşılmak hedeflenmiştir.

\section{Veri Toplama Süreci ve Veri Analizi}

Araştırma verileri yarı yapılandırılmış görüşme tekniği ile toplanmıştır. Nitel araştırmalarda katılımcıların deneyimleri yarı yapılandırılmış görüşme tekniği ile belirlenebilmektedir (Creswell ve Poth, 2016). Yarı yapılandırılmış görüşme formu, karmaşık ve bazen hassas konulara ilişkin katılımcıların algıları ve fikirlerinin araştırılması için çok uygundur ve daha zengin yanıtların netleştirilmesi için araştırmaya olanak tanır (Louise Barriball ve While, 1994). Bu çalışmada katılımcıların çevrimiçi mutlu okul olgusuna ilişkin deneyim, alg1 ve fikirlerini ortaya çıkarmak amacıyla; "Sizi çevrimiçi eğitimde neler mutlu etmektedir?" şeklinde bir sorudan oluşan yarı yapılandırılmış görüşme formu hazırlanmıştır.

Araştırmada gönüllülük esasına göre telekonferans aracılığıyla gerçekleştirilen görüşme verileri içerik analizi ile çözümlenmiştir (Giorgi, 1997). İçerik analizinde şu basamaklar izlenmiştir: Birinci aşamada gerçekleştirilen tüm görüşmeler yazıya dökülmüştür. Yazıya dökülen veri seti ve alan yazın okunmaları sonucunda kodlar oluşturulmuştur. Üçüncü aşamada ise ortaya çıkan kodlar benzer kodlarla birleştirilerek temalar belirlenmiştir. Temalar altında 
birleştirilen kodlar yeniden gözden geçirilerek düzenlenmiştir. En son aşamada ise kodlar ve temalar olarak araştırma bulguları ortaya çıkarılmıştır.

\section{Bulgular ve Yorumlar}

$\mathrm{Bu}$ çalışmada öğrenci, veli ve öğretmenlerin mutlu çevrimiçi okula ilişkin deneyimleri araştırılmıştır. Araştırma verilerinin analizi sonucunda elde edilen bulgular alt problemlerin sırasına göre verilmiştir.

\section{Çevrimiçi Mutlu Öğrenci}

Araştırmanın ilk alt problemi "Öğrenciler çevrimiçi okulda nelerden mutlu olmaktadırlar?" şeklindedir. Bu problem doğrultusunda öğrencilere "Sizi çevrimiçi eğitimde neler mutlu etmektedir?" şeklinde bir soru sorulmuştur. Öğrenci yanıtları analiz edildikten sonra ulaşılan sonuçlar Tablo 1'de raporlanmıştır:

\begin{tabular}{|c|c|c|c|}
\hline \multicolumn{4}{|c|}{$\begin{array}{l}\text { Tablo } 1 \\
\text { Öğrencilerin Çevrimiçi Mutlu Okula İlişkin Görüşleri. }\end{array}$} \\
\hline Temalar & Kodlar & f & $\%$ \\
\hline \multirow[t]{3}{*}{ Eğlence } & Ders öncesi sohbet & 32 & $\% 57.1$ \\
\hline & Ders içi gizli sohbet & 9 & $\% 16.1$ \\
\hline & Ders arası bilgisayar & 16 & $\% 28.5$ \\
\hline \multirow[t]{4}{*}{ Kolaylık } & Sınıf içi iletişimi kolaylaştırma & 29 & $\% 51.7$ \\
\hline & Dersi kaynatmayı kolaylaștırma & 7 & $\% 12.5$ \\
\hline & Devamsızlığı kolaylaştırma & 4 & $\% 7.1$ \\
\hline & Bahaneleri kolaylaştırma & 3 & $\% 5.3$ \\
\hline \multirow[t]{3}{*}{ Özgürlük } & Bilgisayar ve tablet yasağ & 26 & $\% 46.4$ \\
\hline & Teknolojik alet alabilme & 21 & $\% 37.5$ \\
\hline & Öğretmen otoritesi & 9 & $\% 16.1$ \\
\hline \multirow[t]{3}{*}{ Esneklik } & Zaman esnekliği & 13 & $\% 23.2$ \\
\hline & Uygulama içi esneklik & 11 & $\% 19.6$ \\
\hline & Hareket esnekliği & 6 & $\% 10.7$ \\
\hline
\end{tabular}

Tablo 1'de ifade edildiği gibi öğrencilerin mutlu çevrimiçi okula ilişkin görüşleri eğlence, kolaylık, özgürlük ve esneklik temalarında toplam 13 kod ile açıklanmıştır. Eğlence temasında ders öncesi arkadaşları ile sohbet $(\% 57.1)$, ders içi gizli sohbet $(\% 16,1)$ ve ders arası bilgisayarla baş başa kalma (\%28.5) kodlarında mutluluk ifade edilmiştir. Eğlence temasına ilişkin öğrenci ifadesi şu şekildedir:

“... programına bağlandığımızda öğretmen gelmeden arkadaşlarımla sohbet etmek çok eğlenceli. Hatta çoğu defa erken girip konuşuyoruz. Ö5"

"En çok özlediğim okulda arkadaşlarımdı. Bu derslerde arkadaşlarımı görmek çok güzel.

Ders yokken öğretmen yokken, çılgınlar gibi eğleniyoruz. Ö26" 
Öğrenciler eğlence temasından sonra en çok kolaylık temasında mutluluk belirtmişlerdir. Kolaylık temasında, sınıf içi iletişimi kolaylaştırma (\%51.7), dersi kaynatmayı kolaylaştırma

(\%12.5), devamsızlığı kolaylaştırma (\%7.1) ve bahaneleri kolaylaştırma (\%5.3) kodlarında öğrenciler mutlu olduklarını ifade etmişlerdir. Kolaylık temasına örnek olarak bazı öğrenci görüşleri aşağıda verilmiştir.

“ Sınıfta öğretmene ne zaman bir şey diyecek olsam çok kolay. Söyleyemesem yazarım. Yani ister gizli ister herkese açık yazarım. Öyle yani çok kolay. Ö13”

“ Okulda sesim çıkmıyordu çok. Şimdi burada ne zaman içimden bir şey söylemek gelse hemen duyuluyor. Öğretmen gerektiği zaman sesimizi kapatıyor da. Hep önde oturuyor gibiyim.Ö2"

"Bazen bir sorun oluyor. Karışıyor. Donma oluyor. Bağlantı kopuyor. Dersin yarısı kaynıyor. Sevmediğim ders olunca mutlu oluyorum. Ö8”

Öğrencilerin mutlu olduğu bir diğer tema ise özgürlük olarak isimlendirilmiştir. Özgürlük temasında, bilgisayar ve tablet yasak değil (\%46.4), teknolojik alet alabilme (\%37.5) ve öğretmenimiz üzerimizde baskı kurmuyor (\%16.1) kodları belirtilmiştir. Özgürlük teması kodlarına ilişkin bazı örnekler şu şekildedir.

“ Beş yıllık öğrencilik hayatımda ilk defa toplamadık bilgisayarı. Bence mutluluk bu. Ö48"

“Babam istediğim kulaklığı aldı. Kulaklığı çok seviyorum. Babamı çok seviyorum. Beni mutlu ettiği için. Ö 32”

“ Öğretmen çok bağırırdı. Korkardım. ... 'da bağırmıyor. Ö15”

Öğrencilerin ifadeleri son olarak esneklik temasında konumlanmıştır. Esneklik başlığı altında, zaman esnekliği (\%23.2), uygulama içi esneklik (\%19.6) ve hareket esnekliği (\%10.7) kodları öğrencileri mutlu etmektedir. Esneklik temasında iki öğrencinin ifadeleri aşağıda olduğu gibi belirtilmiştir.

“Sabah erken kalkmamak çok mutlu. Geç kalkıyorum. Arada yemek yiyorum. Ö27”

" Mikrofonu kamerayı kapatıp tuvalete gidebiliyorum. Yorulursam yatarak da oluyor. Ö8”

\section{Mutlu Çevrimiçi Veli}

Araştırmanın ikinci alt problemi "Veliler çevrimiçi okulda nelerden mutlu olmaktadırlar?" şeklindedir. Bu problem doğrultusunda velilere "Sizi çevrimiçi eğitimde neler mutlu etmektedir?" şeklinde bir soru sorulmuştur. Veli yanıtları analiz edildikten sonra ulaşılan sonuçlar Tablo 2'de raporlanmıştır: 


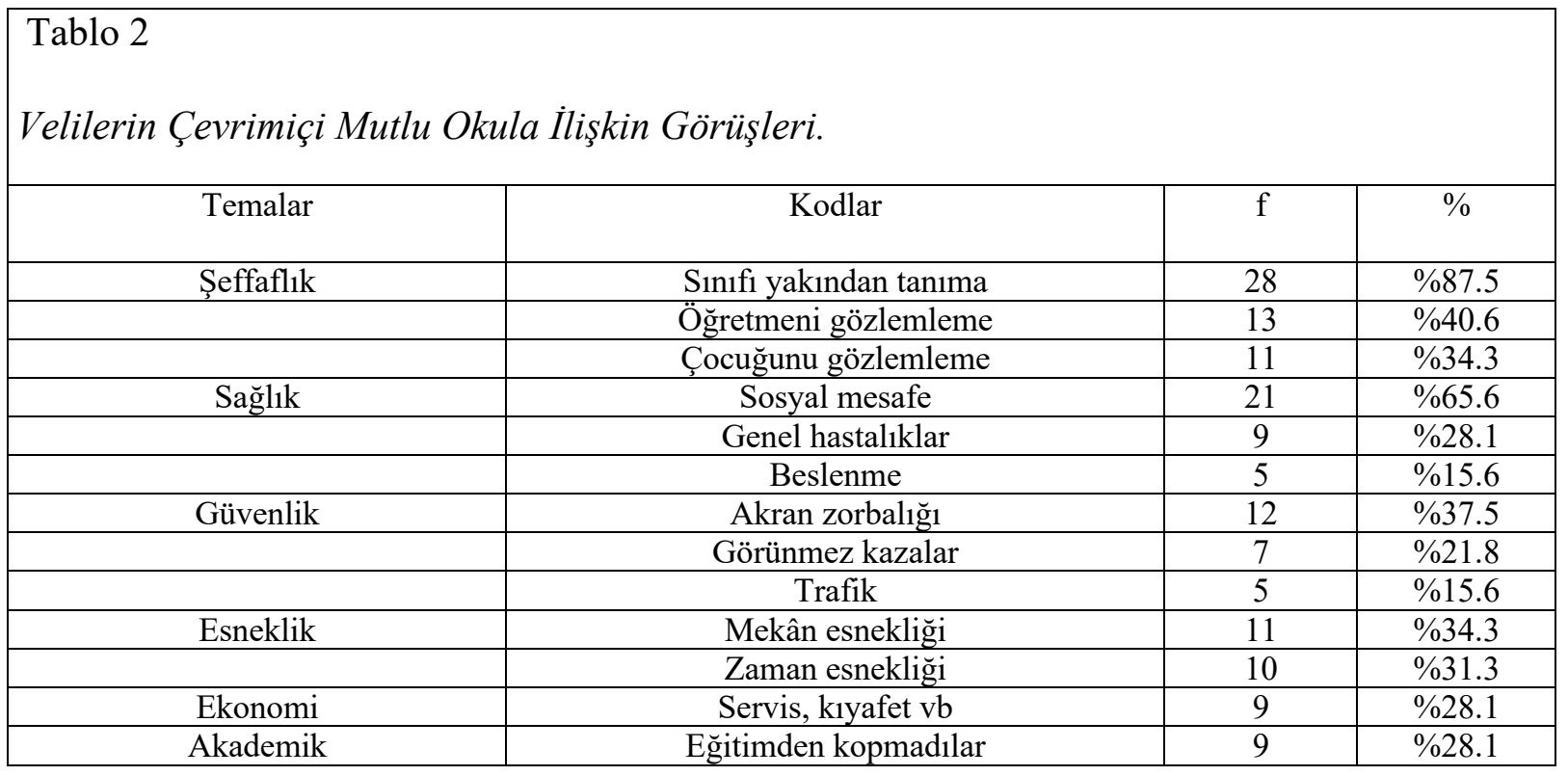

Tablo 2'de ifade edildiği gibi velilerin mutlu çevrimiçi okula ilişkin görüşleri şeffaflık, sağlık, güvenlik, esneklik, ekonomi ve akademik temalarında toplamda 13 kod ile açıklanmıştır. En sık görüş belirtilen şeffaflık temalarında, sınıfı yakından tanıma (\%87.5), öğretmeni gözlemleme (\%40.6) ve kendi çocuğunu gözlemleme (\%34.3) kodları dile getirilmiştir. Veli görüşlerinde en sık dile getirilen ifadelerden ikisi şu şekildedir:

"Bütün arkadaşlarını görmek. Onlarla diyaloğunu bilmek. V4"

"Bizim bir bulaşık makinemiz vardı. Deterjan içinde bütün kalıyordu. Servis çağırdık şeffaf bir kapak taktılar. Ve gördük ki, deterjan son dakikalarda düşüyor. E haliyle yıkamıyor. Bu da öyle oldu. Kızımla ilgili kafamdaki sorular aydınlandı. V21”

Öte yandan velilerin en sık ifade ettikleri görüşlere göre çevrimiçi okul sağlık bağlamında mutluluk kaynağıdır. Sağlık temasında, sosyal mesafe (\%65.6), genel hastalıklar (\%28.1) ve beslenme (\%15.6) kodlarında veliler mutluluk ifadeleri belirtmişlerdir. Mutlu veliler şu ifadeleri kullanmıştır.

“Çocuğum ufak tefek rahatsızlandığında okula göndermek zorunda kaldığımda o gün aklım da onda kalıyordu. Şu an gözümün önünde hem tedavisini sürdürebilir herhangi bir durumda müdahale ederken eğitimi de devam edebilir. V19”

Velileri mutlu eden bir diğer tema ise güvenlik olarak isimlendirildi. Mutlu çevrimiçi veliler güvenlik temasında, akran zorbalığı (\%37.5), görünmez kazalar (\%21.8) ve trafik kodlarında (\%15.6) görüş belirtmişlerdir. Güvenlik temasında şu ifadeler doğrudan veli görüşlerine örnek olarak alınmıştır. 
"Sabah bir telaş, akşam bir telaş,, Gitti mi geldi mi acaba şu an ne yapıyor, serviste sorun çıktı mı bir sürü soru işareti kafamızda dönüp duruyordu. Şimdi odasında aralarda konuşuyoruz. V1"

"Benimkinin kavga etmediği gün yoktu. Acaba bugün ne olacak diye korka çekine gönderdim sabahları. V25"

Velilerin mutlu çevrimiçi okula ilişkin görüşleri esneklik temasında ise mekan esnekliği (\%34.3) ve zaman esnekliği (\%31.3) kodlarından oluşmaktadır. Ayrıca ekonomi temasında servis, kıyafet ve benzeri (\%28.1) kodlarında veliler mutlu olduklarını belirtmişlerdir. Son olarak akademik teması altında, eğitimden kopmadılar (\%28.1) kodu bulunmaktadır. Veliler mutlu çevrimiçi okulu akademik olarak eğitimden kopmamak olarak algılamaktadırlar. Eğitimden ve okuldan kopmama durumu mutluluk sebebi olmaktadır.

\section{Mutlu Çevrimiçi Öğretmen}

Araştırmanın üçüncü alt problemi "Öğretmenler çevrimiçi okulda nelerden mutlu olmaktadırlar?” şeklindedir. Bu problem doğrultusunda öğretmenlere "Sizi çevrimiçi eğitimde neler mutlu etmektedir?” şeklinde bir soru sorulmuştur. Öğretmen yanıtları analiz edildikten sonra ulaşılan sonuçlar Tablo 3'te raporlanmıştır:

Tablo 3

Öğretmenlerin Çevrimiçi Mutlu Okula İlişkin Görüşleri.

\begin{tabular}{|c|c|c|c|}
\hline Temalar & Kodlar & $\mathrm{f}$ & $\%$ \\
\hline Sağlık & Sosyal mesafe & 14 & $\% 82.3$ \\
\hline & Sağglı sorunlarına uyumlu & 10 & $\% 58.8$ \\
\hline Kolaylık & Hayatı kolaylaştırma & 12 & $\% 70.5$ \\
\hline & Sinıf yönetimi & 7 & $\% 41.1$ \\
\hline & İcerik paylaşma & 6 & $\% 35.2$ \\
\hline & Ek ders planlama & 5 & $\% 29.4$ \\
\hline & Veli işbirliği & 5 & $\% 29.4$ \\
\hline & Mesleki gelişim & 9 & $\% 52.9$ \\
\hline İnovasyon & Teknolojik gelişim & 7 & $\% 41.1$ \\
\hline & Yeni öğrenme kanalları edinme & 3 & $\% 17.6$ \\
\hline & Öğrencilerime daha fazla zaman & 8 & $\% 57.1$ \\
\hline Zaman & Kendime daha fazla zaman & 5 & $\% 29.4$ \\
\hline & Aileme daha fazla zaman & 2 & $\% 17.6$ \\
\hline
\end{tabular}

Tablo 3 'te ifade edildiği gibi öğretmenlerin mutlu çevrimiçi okula ilişkin görüşleri sağlık, kolaylık, inovasyon ve zaman temalarında toplamda 13 kod ile açıklanmıştır. Sağlık temasında, sosyal mesafe (\%82.3) ve sağlık sorunlarına uyumlu (\%58.8) kodlarının en sık dile getirildiği görülmüştür. Burada sağlık temasına ilişkin öğretmen ifadeleri şu şekildedir:

"Bende bel fitığı var hocam. Belim çok ağrıyınca kamerayı kapayıp uzanıyorum. Ne yalan söyleyeyim buna bay1lıyorum. T10" 
“Senden büyüğüm öğretmenim ben. Haliyle risk gurubundayım. Sosyal mesafe olmazsa nasıl olur bilmiyordum. İçim rahatladı uzaktan olunca. T3”

Öğretmen görüşlerinde mutluluk ifadeleri kolaylık temasında birleştirilmiştir. Kolaylık bağ lığı altında, hayatı kolaylaştırma (\%70.5), sınıf yönetimi (\%41.1), içerik paylaşma (\%35.2) ek ders planlama (\%29.4) ve veli işbirliği (\%29.4) kodları yer almaktadır. Öğretmenler şu ifadelerinde çevrimiçi okulun kolaylıkları görülmektedir.

"Çocukların sesini istediğinde kapatabilmek. T9"

"Mesleği daha çok sevmeye başladım. Ben uzaktan öğretmen olmak için doğmuşum. O kolay, bu kolay ne bileyim yapmak isteyip de yapamadığım her şey çok kolaylaştı. T1" "Velilerim beni mutlu ediyor. Etmeyenler de yok değil de. Mutlu edenler çok daha iyi.

Bir nevi yardımcı öğretmen gibi her işe koşturuyorlar. T16"

Öte yandan öğretmen görüşlerinde çevrimiçi okul bir inovasyon olarak mutluluk üretmektedir. İnovasyon temasında, mesleki gelişim (\%52.9), teknolojik gelişim (\%41.1) ve yeni öğrenme kanalları edinme (\%17.6) kodları mutluluk nedeni olarak sıralanmaktadır. Öğretmen görüşleri bu başlikta şu şekildedir:

"Bir devrim bu. Online sınıf bambaşka bir duygu. Farklı bir olay, Sadece bir değişim değil çok daha ötesi diyebilirim. Zorla değiştik. İster istemez dönüştük. T1”

"Ben lisedeyken okula bilgisayar gelmişti. Koskoca bir ders açıp kapamasını öğrenmiştik sadece. Şimdi çocuklar birinci sınıfta türlü türlü şeyler biliyorlar. Öğretmen de öğrenci de çok değişti. T5"

Öğretmen görüşlerine göre oluşturulan temaların en sonunda zaman yer almaktadır. Zaman temasında, öğrencilerime daha fazla zaman (\%57.1), kendime daha fazla zaman (\%29.4) ve aileme daha fazla zaman (\%17.6) kodları belirtilmektedir. Öğretmenler şu ifadeleri ile zaman temasında mutluluk belirtmişlerdir:

“ Hazırlık, yol ve boş dersler fillan toplayınca ne kadar ölü zamanım olduğunu yeni keşfettim. Eskiden birazcık farkında olduğumu sanıyordum da ama epey çokmuş. Hayatımız yollarda bitmiş de haberimiz olmamış. T2 "

“Öğrencilerime bireysel ilgi sunmak çok zevkli. Ek dersler ayarlıyor onlarla gerekli görürsem bire bir çalışma yapıyorum. İşe yarayınca da çok mutlu oluyorum. T8” 


\section{Sonuçlar}

$\mathrm{Bu}$ araştırmada öğrenci, veli ve öğretmen katılımcıların çevrimiçi mutlu okula yönelik deneyimleri incelenmiştir. Araştırmanın bulgularına göre, mutlu çevrimiçi okul, öğrencilerin, velilerin ve öğretmenlerin çevrimiçi öğrenmede yaşadıkları mutluluklar üzerinden açıklanmıştır (Grafik 1).

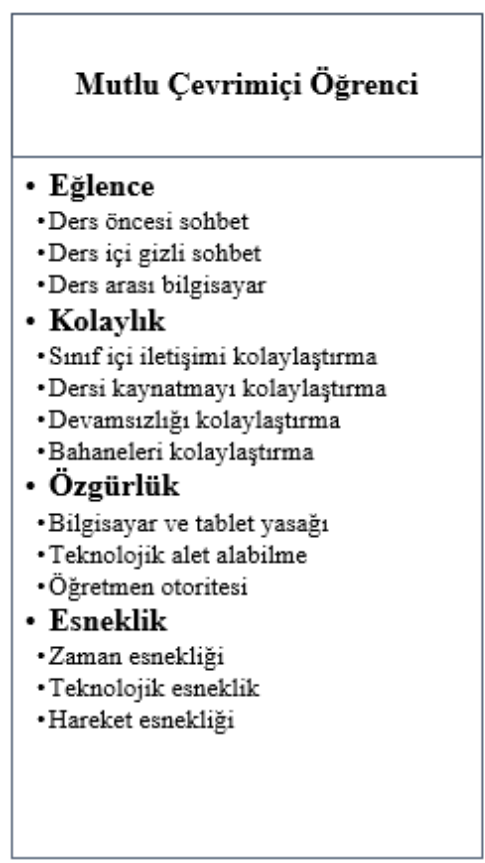

\begin{tabular}{|c|}
\hline Mutlu Çevrimiçi Veli \\
\hline 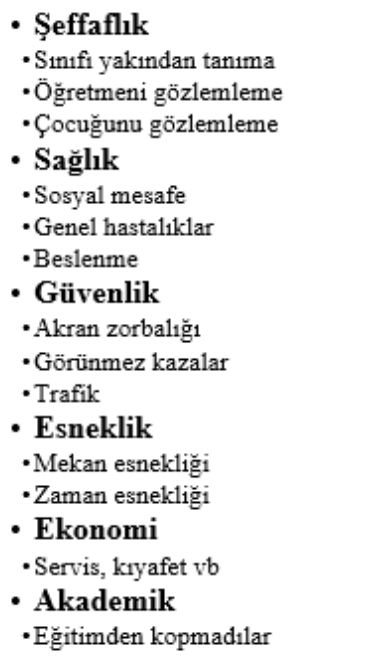 \\
\hline
\end{tabular}

\begin{tabular}{|c|}
\hline Mutlu Çevrimiçi Öğretmen \\
\hline $\begin{array}{l}\text { - Sağlik } \\
\text {-Sosyal mesafe } \\
\text { - Sağlik sorunlarına uyumlu } \\
\text { - Kolaylik } \\
\text { - Hayatı kolaylaştırma } \\
\text { - Sinıf yönetimi } \\
\text { - Içerik paylaşma } \\
\text {-Ek ders planlama } \\
\text { - Veli işbirliği } \\
\text { - İnovasyon } \\
\text { - Mesleki gelişim } \\
\text { - Teknolojik gelişim } \\
\text { - Yeni oggrenme kanalları edinme } \\
\text { - Zaman } \\
\text { - Öğrencilerime daha fazla zaman } \\
\text { - Kendime daha fazla zaman } \\
\text { - Aileme daha fazla zaman }\end{array}$ \\
\hline
\end{tabular}

Grafik 1. Mutlu Çevrimiçi Okula İlişkin Öğrenci, Veli ve Öğretmen Görüşleri

Grafik 1 üzerinde görülebileceği gibi, mutlu çevrimiçi öğrenci, mutlu çevrimiçi veli ve mutlu çevrimiçi öğretmen birleşiminde mutlu çevrimiçi okul açıklanmaya çalışılmıştır. Alan yazında bu bulguları destekleyen çalışmalar mevcuttur. Örneğin Fidan (2020a) tarafından yapılan çalışmada mutlu okul, öğrenci, öğretmen, veli, çalışan ve yönetici mutluluklarının bütünü olarak ifade edilmiştir. Yüz yüze eğitim sürecinde gerçekleştirilen ilgili çalışmadaki mutlu okul, çevrimiçi okulların mutluluklarını inceleyen bu çalışma ile güncellenmiştir. Dolayısıyla geleneksel okulun mutluluklarının yanına yeni mutluluklar eklenmiştir.

Mevcut pandemi, eğitimciler, uygulayıcılar ve araştırmacılar için geçmişte geleneksel eğitime iyi hizmet etmiş olanı sürdürmek, işe yaramayanlardan da kopmak ve yeniyi hayal etmeye başlamak için eşsiz bir firsat sunmaktadır (Langlois ve ark., 2020). Shearer ve diğerleri (2020) tarafından yapılan çalışmada, çevrimiçi okulun geleneksel yüz yüze eğitimde edinilen deneyimlerin kopyasından ibaret olmadığ1; bu deneyimlerin geliştirilerek dönüştürülmesiyle çevrimiçi mutlu okulun oluşturulabileceği vurgulanmaktadır.

\section{Mutlu Çevrimiçi Öğrenci}


Araştırmaya katılan öğrenciler çevrimiçi okulda, eğlence, kolaylık, özgürlük ve esneklik temalarında mutlu olduklarını belirtmişlerdir. En çok görüş belirtilen eğlence teması, öğrencilerin arkadaşları ve bilgisayarıyla ders içi ve ders arası mutluluklarından oluşmaktadır. Eğlence temasına ilişkin mutluluk bulgusu alan yazın ile örtüşmektedir. Geleneksel okulda yapılan mutluluk çalışmalarında öğrencilerin mutluluk nedenlerinin başında oyun ve eğlence gelmektedir (Döş, 2013; Fidan, 2020a; Ünüvar ve ark., 2015). İlgili bilimsel çalışmaları destekler şekilde Millî Eğitim Bakanlığının (10/7/2019 tarihli yönetmelik) teneffüsleri 15 dakikaya çıkarması öğrencileri okulda mutlu etmeye dönük adımlardan olmuştur. Pandemi döneminde yüz yüze eğitime ara verilmesiyle teneffüslere de ara verilmiştir. Dolayısıyla öğrencilerin sosyalleşme, sohbet etme ve arkadaşları ile eğlenme gereksinimleri çevrimiçi teneffüslerde sağlanmak durumundadır. Yapılan çalışmalarda pandemi koşularında hızla yaygınlaşan başarılı çevrimiçi uygulamalar sayesinde çocukların sağlığına ve mutluluğuna destek olunduğu vurgulanmaktadır (Burns ve Gottschalk, 2020).

Araştırmaya katılan öğrencilerin mutluluk ifadeleri ikinci olarak kolaylık temasında kümelenmektedir. Öğrenciler çevrimiçi derslerinde iletişimin, dersi kaynatmanın, devamsızlığın ve bahanelerin kolaylaştığını mutlulukla ifade etmektedirler. İlk bakışta bu ifadeler olumsuz algılanabilir. Ancak öğrenci psikolojisi bu gibi durumları mutluluk olarak değerlendirebilmektedir. Alan yazında yer alan son çalışmalarda öğrencilerin çevrimiçi dersleri bu ve benzeri kolaylıklar nedeniyle, akademik olarak başarılı görmedikleri ifade edilmektedir (Trout, 2020). Benzer bir çalışmada, öğrencilerin çevrimiçi derslerde devamsızlık ve benzeri sorunlarına dikkat çekilmektedir (Lie ve ark., 2020). Bir diğer çalışmada ise öğrencilerin kolay seçeneklere yönelmeleri sonucu ortaya çıkan zorluklar vurgulanmaktadır (Suryaman ve ark., 2020). Bu sonuçların öğretmen, veli ve diğer ilgililerce bilinmesi önemli görülmektedir.

Araştırmaya katılan öğrenci görüşlerinin kümelendiği bir diğer tema ise özgürlük olarak isimlendirilmiştir. Öğrenciler özgürlük temasında, geleneksel öğretim dönemlerinde yasak olan bilgisayar ve tabletin artık serbest olmasını mutluluk olarak belirtmektedirler. Ayrıca teknolojik araçlara olan bakış açısının değişmesi ve teknolojik alet aldırabilme özgürlüğü öğrencileri mutlu etmektedir. Alqahtani ve Rajkhan (2020) tarafından yapılan çevrimiçi eğitimde başarı kriterleri çalışması, bu sonuçları desteklemektedir. Buna göre teknolojiye yönelik bakış açısı ve çevrimiçi öğretime hazır olmanın pandemi sürecinde başarıyı artırdığı belirlenmiştir. Öte yandan öğrenciler öğretmenler karşısında daha özgür olduklarını mutlulukla ifade etmektedirler. English ve Stengel (2010) tarafından yapılan çalışmada, korkunun çeşitli nedenlerle öğrenme sürecine girdiği ve olumsuz etkileri olduğu ifade edilmektedir. Keeling ve Haugestad (2020) tarafından yapılan çalışmada ise çevrimiçi derslerin daha çok öğrenci 
merkezli olduğuna vurgu yapılmaktadır. Dolayısıyla çevrimiçi okulda öğrencilerin korkudan özgürleşmesi olumlu bir durumdur.

Araştırmaya katılan öğrencilerin görüşleri son olarak esneklik başlığında kategorileştirilmiştir. Zaman, teknoloji ve hareket esnekliği öğrencileri çevrimiçi okulda mutlu etmektedir. Alan yazında benzer çalışma bulguları yer almaktadır. Örneğin Dwivedi ve diğerleri (2020) tarafından yapılan çalışmada çevrimiçi eğitimdeki esnekliğin olumlu algılandığı belirtilmektedir. Benzer şekilde Keeling ve Haugestad'ın (2020) çalışma sonuçları çevrimiçi eğitimin esnek yapısının öğrenciler tarafından beğenildiği yönündedir. Bir diğer çalışmada ise Daniel (2020), zaman ve benzeri esnekliklerin çevrimiçi eğitimde olumlu olduğunu ve öğrenciler tarafından benimsenmekte olduğunu belirtmektedir. Çevrimiçi okulda öğrenciyi mutlu eden tüm temalar öğrencileri derse motive ettikleri için önemlidir. Çünkü uzaktan öğretim sürecinde öğrencilerin iç motivasyonu ön plandadır (Fırat ve ark., 2018).

\section{Mutlu Çevrimiçi Veli}

Araştırmaya katılan veliler çevrimiçi okulda, şeffaflık, sağlık, güvenlik, esneklik, ekonomi ve akademik temalarında mutlu olduklarını belirtmişlerdir. En çok mutluluk ifade edilen şeffaflık, sınıfı yakından tanıma, öğretmeni gözlemleme ve kendi çocuğunu gözlemleme kodlarından oluşmaktadır. Bu bulgu alan yazınla benzerlik göstermektedir. Brom ve diğerleri (2020) tarafından yapılan çalışmada velilerin birçok görevle çevrimiçi eğitime dahil olduğu belirtilmektedir. Buna göre çevrimiçi öğrencilerin büyük bir kısmına velilerinin yardım etmekte olduğu, bunun yanında kontrol ve geribildirim gibi görevlerin veliler tarafindan yapıldığı, ayrıca az da olsa bazı velilerin bir öğretmen rolünde yeni konular öğretmekte olduğu belirtilmektedir. Benzer şekilde Garbe ve diğerleri (2020) tarafından yapılan çalışmada, velilerin çevrimiçi derslere katılım sağlamaktan mutlu oldukları belirtilmektedir. Bir başka çalışmada ise (Bhamani ve ark., 2020) velilerin ortaya çıkan öğrenme boşluğunu gidermek için hızla adapte oldukları ve mutlulukla sürece katıldıkları belirtilmektedir.

Araştırmaya katılan velilerin çevrimiçi okula ilişkin görüşleri şeffaflık temasından sonra en sık sağlık temasında kümelenmektedir. Sağlık temasında, sosyal mesafe, genel hastalıklar ve sağlıklı beslenme kodlarında velilerin mutlu oldukları görülmektedir. Yapılan çalışmalarda salgının ilk dönemindeki büyük stres nedeniyle ailelerin sağlı bağlamında oldukça hassas oldukları vurgulanmaktadır (Susilowati ve Azzasyofia, 2020). Zamanla çevrimiçi okula alışan velilerin diğer hastalıklar bağlamında da durumdan mutlu oldukları görülmektedir. Ayrıca küçük rahatsızlıklar durumunda sağlıklı beslenmesi gereken öğrencilerin evde yanlarında olması velileri mutlu etmektedir. Benzer şekilde veliler öğrencilerin evde gözlerinin önünde olmasının daha güvenli olduğu gerekçesiyle mutlu olunduğunu belirtmektedirler. Coppola ve 
diğerleri (2020) tarafından yapılan çalışmada acil uzaktan öğretim sürecinde velilerin en temel odaklandıkları iki konunun sağlık ve güvenlik olduğu belirtilmektedir.

Araştırmaya katılan veliler esneklik temasında değerlendirilen mekan ve zaman esnekliği kodlarında mutludurlar. Benzer çalışmalar velilerin çevrimiçi eğitimin esneklik özelliğinden mutlu olduklarını ortaya koymaktadır (Brom ve ark., 2020; Suryaman ve ark., 2020). Rahman ve diğerleri (2020) esnekliğin çevrimiçi okul için önemli olduğunu vurgulamaktadır. Buna göre veliler çevrimiçi okulda zaman ve mekan kısıtlaması olmadan öğrencilerinin gelişimini planlayabilmektedir. Pandemiden yüksek düzeyde etkilenen İtalya örneğinde yapılan bir çalışmada, sürecin bütün risklerinin yanında eğitim bağlamında bir şeylerin yapılabilmesine olanak sağlayan esneklik, veliler tarafından olumlu olarak ifade edilmektedir (Coppola ve ark., 2020). Kuşkusuz buradaki mutluluk, bütün bu sıkıntı ve zorluklar içerisinde bir şeyleri başarmanın mutluluğudur ve çok değerli olduğu düşünülmektedir.

Araştırmaya katılan velileri çevrimiçi okulda mutlu eden bir diğer tema ise ekonomi olarak isimlendirilmektedir. Pandemi koşullarında ekonomik sıkıntılar yaşayan veliler, çocukların evde kalmasıyla eğitim masraflarından bir ölçüde kurtulmaktadırlar. Alan yazında pandemi sürecinde velilerin ekonomik olarak desteklenmesi gerektiğine ilişkin çalışmalar bulunmaktadır (Patrick ve ark., 2020). Bu çalışmalarda çok yönlü ekonomik kayıplar ve çevrimiçi eğitime katılım için teknolojik aletlere harcanan maliyetler nedeniyle, velilerin mutlu olmadığı vurgulanmaktadır. Alqahtani ve Rajkhan (2020) tarafından yapılan çalışma sonuçları da bu çalışma ile örtüşmemektedir. Burada teknolojik alt yapı ve erişim harcamaları nedeniyle çevrimiçi okulun ekonomik olarak mutluluk sağlamayacağı belirtilmektedir. Bir diğer araştırma sonuçları da (Gassman-Pines ve ark., 2020) yine benzer gerekçelere ek iş kaybı, gelir kaybı ve bakım yükü nedenleri ile mutsuzluğa vurgu yapmaktadır.

Katılımcı velilerin mutluluğa ilişkin görüşleri son olarak akademik temasında belirtilmiştir. Burada velilerin akademik olarak beklentilerinin düşük olduğu ya da akademik olarak çok da mutlu olmadıkları yorumu yapılabilir. Coppola ve diğerleri (2020) tarafindan yapılan çalışma sonuçları bu çalışma ile örtüşmektedir. İlgili çalışmada velilerin çevrimiçi okulda akademik yönden sorunlarla karşılaştıkları ancak sağlık ve güvenlik endişeleri nedeniyle akademik sorunların ön plana geçemediği ifade edilmektedir. Benzer şekilde Susilowati ve Azzasyofia, (2020) tarafından yapılan çalışma sonuçlarında çevrimiçi okulun akademik olarak istenilen mutluluğu veremediği belirtilmektedir. Akademik eksikliği birçok veli yardım ederek çok azı ise öğrenci yerine kendi yaparak gidermektedir. Hatta bazı velilerin çocuklarına yarı zamanlı öğretmenlik yaptığı ifade edilmektedir (Brom ve ark., 2020). Dolayısıyla pandeminin ilk döneminde gerçekleşen uygulamaya göre çevrimiçi okulun velileri 
akademik olarak mutlu etmediği söylenebilir. En azından şeffaflık, sağlık, güvenlik ve esneklik temaları kadar mutlu etmemektedir.

\section{Mutlu Çevrimiçi Öğretmen}

Araştırmaya katılan öğretmenler çevrimiçi okulda, sağlık, kolaylık, inovasyon ve zaman temalarında mutlu olduklarını belirtmişlerdir. En çok mutluluk ifade edilen sağlık teması, sosyal mesafe ve genel sağlık sorunlarına uyumluluk kodlarından oluşmaktadır. Alan yazında bu sonuçları destekleyen çalışmalar bulunmaktadır. Daniel (2020), sosyal mesafe nedeniyle oluşan zorunlulukta ortaya çıkan çevrimiçi okulun öğrenci, öğretmen ve velileri rahatlattığını belirtmektedir. Benzer şekilde Brom ve diğerleri (2020) tarafından yapılan çalışmada ortaya çıkardığı diğer sorunlar göz ardı edildiğinde çevrimiçi okulun sosyal mesafe bağlamında olumlu etkisi belirtilmektedir. Öte yandan genel hastalıklar bağlamında öğretmen görüşlerinde çevrimiçi okulun mutluluk verici olduğu görülmektedir. Öğretmenler ses kısıklığı, faranjit ve bacak ağrısı gibi sık karşılaşılan hastalıkların (Uzuner ve ark., 2015) çevrimiçi okulda bulunmadığını mutluluk olarak nitelemektedirler.

Araştırmaya katılan öğretmenler çevrimiçi okulda mutluluğa ilişkin kolaylık temasında görüşler belirtmişlerdir. Kolaylık temasında, hayatı kolaylaştırma, sınıf yönetimini kolaylaştırma, ek ders planlamayı kolaylaştırma ve veli işbirliğini kolaylaştırma kodlarında biriken görüşler bulunmaktadır. Kolaylık temasına ilişkin sonuçların alan yazında desteklendiği görülmektedir. Örneğin Tandon (2020) tarafından yapılan çalışmada çevrimiçi okulun kolaylaştırıcı etkisine vurgu yapılmaktadır. Öğretmenler kolaylaştırıcı etkinin tutum ve davranışlara olumlu yansımalarını ifade etmektedirler. Benzer şekilde Fidan (2020b) tarafından yapılan çalışma sonuçlarına göre, öğretmenler çevrimiçi okulun mesleki ve özel hayatlarında birçok kolaylık sağladığını belirtmektedirler. Öğretmenin temel rolünün, başkalarında öğrenmeyi kolaylaştırmak (Keller, 1968) olmasından hareketle, çevrimiçi okulun kolaylık bağlamında öğretmeni mutlu etmesi önemlidir.

Ayrıca araştırma sonuçlarında görülen sınıf yönetiminin kolaylaştı̆̆ı bulgusu alan yazınla örtüşmektedir. Sokal ve diğerleri (2020) tarafından yapılan çalışmada öğretmen görüşleri çevrimiçi okulda sınıf yönetiminin kolaylaştığını göstermektedir. Çevrimiçi okulun kolaylaştırma etkisi veli işbirliğinde de görülmektedir. Alan yazında bu bulguları destekleyen çalışmalar mevcuttur. Garbe ve diğerleri (2020), pandemi sürecinde velilere öğrenme konusunda daha fazla sorumluluk yüklendiğini belirtmektedir. Suryaman ve diğerleri (2020) ise benzer şekilde velilerin öğretmen, öğrenci ve okul arasında kilit noktada olması nedeniyle işbirliğini zorunlu olarak artırmak durumunda kaldığını vurgulamaktadır. 
Araştırmaya katılan öğretmenler çevrimiçi okulda inovasyon temasında mutlulukla ilgili görüşler ortaya koymuşlardır. Mesleki gelişim, teknolojik gelişim ve öğrenme kanallarının yenileşmesi kodlarında öğretmenler mutluluk ifade etmektedirler. Bu bulgular alan yazınla örtüşmektedir. Örneğin Fidan (2020b) tarafından yapılan çalışmada öğretmenler, çevrimiçi eğitim sürecinde mesleki ve teknolojik inovasyon yaşadıklarını belirtmektedirler. Benzer şekilde çevrimiçi okulun büyük bir inovasyon olduğu alan yazında yer almaktadır (Burns ve Gottschalk, 2020; Sculi ve ark., 2020). Sculi ve diğerleri (2020) tarafından yapılan çalışma sonuçlarına göre çevrimiçi okul, mesleki gelişim, teknolojik gelişim, öğretim yöntemleri, materyaller gibi sayısız alanda inovasyon ortaya çıkarmıştır. Sharif ve diğerleri (2020) tarafından yapılan çalışmada çevrimiçi okulda inovasyonu benimseme ve avantajlara liderlik etmeye odaklanmak gerekliliği belirtilmektedir.

Araştırmaya katılan öğretmen görüşleri son olarak zaman temasında ifade edilmiştir. Öğrencilere, ailelerine ve kendilerine daha çok zaman ayırabilme öğretmenleri mutlu etmektedir. Alan yazında bu bulguları destekler nitelikte çalışmalar görülmektedir. Örneğin Hebebci ve diğerleri (2020) tarafından yapılan çalışmada öğretmenlerin zaman bağlamında olumlu ifadeleri bulunmaktadır. Çevrimiçi okulda yolda geçen zamanlar, boş derslerde geçen zamanlar ve diğer zaman kayıpları olmadığından; öğretmenlerin kendilerine ve ailelerine ayırdıkları zaman artmaktadır. Öğretmenler bu zamanı öğrencilere ek ders planlayarak da değerlendirebilmektedirler (Suryaman ve ark., 2020). Fidan (2020b) tarafindan yapılan çalışmada öğretmenlerin acil uzaktan öğretimin zaman bağlamında olumlu görüşlere sahip oldukları görülmektedir.

\section{Öneriler}

Mevcut pandemi, eğitimciler, uygulayıcılar ve araştırmacılar için geçmişte geleneksel eğitime iyi hizmet etmiş olanı sürdürmek, işe yaramayanlardan da kopmak ve yeniyi hayal etmeye başlamak için eşsiz bir firsat sunmaktadır (Langlois ve ark., 2020). Shearer ve diğerleri (2020) tarafından yapılan çalışmada, çevrimiçi okulun geleneksel yüz yüze eğitimde edinilen deneyimlerin kopyasından ibaret olmadığı; bu deneyimlerin geliştirilerek dönüştürülmesi gerekliliği vurgulanmaktadır. Bu çalışma sonucunda çevrimiçi eğitim bağlamında mutlu çevrimiçi okul önerilmektedir.

Mutlu çevrimiçi okul önerisi, öğrenci, öğretmen ve velileri nelerin mutlu ettiğine dayalı olarak açıklanabilir. Çalışma sonuçlarına göre öğrenciler çevrimiçi okulda eğlence, kolaylık, özgürlük ve esneklik bileşiminde mutludurlar. Dolayısıyla uygulayıcılara ve araştırmacılara mutlu çevrimiçi öğrenci bileşenlerini göz önünde bulundurmaları önerilebilir. Örneğin 
öğrencileri en çok mutlu eden ders içi ve ders öncesi akran iletişimi artırılabilir. Bu amaçla ders içi çevrimiçi teneffüsler planlanabilir. Ayrıca ders arası bilgisayarla baş başa kalma mutluluğu, ders arası araştırma ödevleri veya farklı projelerle değerlendirilebilir.

Çalışma sonuçlarına göre veliler çevrimiçi okulda, şeffaflık, sağlık, güvenlik, esneklik, ekonomi ve akademik bileşiminde mutludurlar. Bu bulgular araştırmacıların derinlemesine çalışmalarında incelenebilir. Ayrıca uygulayıcıların bu mutlu çevrimiçi veli bileşenlerini göz önünde bulundurmaları önerilebilir. Örneğin velilerin şeffaflıktan mutlu olduğu sonucu uygulayıcılara fikir verebilir. Öte yandan akademik mutluluğun son sıralarda da olsa yer bulması önemlidir. Akademik mutluluğu artırıcı çalışmalar yapılması önerilebilir.

Öğretmenlerin mutlu çevrimiçi okul görüşleri ise, sağlık, kolaylık, inovasyon ve zaman bileşiminde ortaya çıkmıştır. Buna göre araştırmacı ve uygulayıcıların mutlu çevrimiçi öğretmen bileşenlerini göz önünde bulundurmaları önerilebilir. Örneğin öğretmenlerin çevrimiçi okuldaki artan sorumlulukları ve karşılaşılan güçlüklere rağmen inovasyondan mutlu olmaları önemlidir. Öğretmenlerin yenilikleri mutlulukla karşılamaları, inovatif eğitimlerle desteklenmeleri için dayanak olabilir. Bu ve diğer mutluluklar çerçevesinde öğretmenlerin güçlendirilmesi dolaylı olarak eğitim öğretimin güçlendirilmesine hizmet edebilir. 


\section{Kaynakça}

Aliyyah, R. R., Rachmadtullah, R., Samsudin, A., Syaodih, E., Nurtanto, M., \& Tambunan, A. R. S. (2020). The perceptions of primary school teachers of online learning during the Covid-19 pandemic period: A case study in Indonesia. Journal of Ethnic and Cultural Studies, 7(2), 90-109.

Alqahtani, A. Y., \& Rajkhan, A. A. (2020). E-learning critical success factors during the covid19 pandemic: A comprehensive analysis of e-learning managerial perspectives. Education Sciences, 10(9), 216-231.

Barton, D. C. (2020). Impacts of the COVID-19 pandemic on field instruction and remote teaching alternatives: Results from a survey of instructors. Ecology and Evolution, 10(22), 12499-12507.

Bates, A. W., \& Bates, T. (2005). Technology, E-Learning and Distance Education. Psychology Press.

Bhamani, S., Makhdoom, A. Z., Bharuchi, V., Ali, N., Kaleem, S., \& Ahmed, D. (2020). Home learning in times of COVID: Experiences of parents. Journal of Education and Educational Development, 7(1), 9-26.

Bozkurt, A., \& Sharma, R. C. (2020). Emergency remote teaching in a time of global crisis due to CoronaVirus pandemic. Asian Journal of Distance Education, 15(1), 1-6.

Brom, C., Lukavský, J., Greger, D., Hannemann, T., Straková, J., \& Švaříček, R. (2020). Mandatory home education during the Covid-19 lockdown in the Czech Republic: A rapid survey of 1st-9th graders' parents. In Frontiers in Education, 5, 103-115.

Brusilovsky, P., Eklund, J., \& Schwarz, E. (1998). Web-based education for all: A tool for development adaptive courseware. Computer networks and ISDN systems, 30(1), 291300.

Burns, T. and F. Gottschalk (eds.) (2020), Education in the digital age: Healthy and happy children, Educational Research and Innovation, OECD Publishing, Paris, https://doi.org/10.1787/1209166a-en.

Coppola, M., Immacolata, S., \& Masullo, G. (2020). Parents in Pandemic: parents’ perceptions of risks and psychological, relational, and pedagogical needs in childhood during the COVID-19 emergency in Italy. http://dspace.epoka.edu.al/handle/1/1881 
Creswell, J. W., \& Poth, C. N. (2016). Qualitative Inquiry and Research Design: Choosing Among Five Approaches. Sage publications

Daniel, S. J. (2020). Education and the COVID-19 pandemic. Prospects, 49, 91-96.

Döş, İ. (2013). Mutlu okul. Eğitim ve Bilim, 38(170), 265-279.

Dwivedi, Y. K., Hughes, D. L., Coombs, C., Constantiou, I., Duan, Y., Edwards, J. S., \& Raman, R. (2020). Impact of COVID-19 pandemic on information management research and practice: Transforming education, work and life. International Journal of Information Management, 55, 102211.

English, A., \& Stengel, B. (2010). Exploring fear: Rousseau, Dewey, and Freire on fear and learning. Educational Theory, 60(5), 521-542.

Firat, M., Kılınç, H., \& Yüzer, T. V. (2018). Level of intrinsic motivation of distance education students in e-learning environments. Journal of Computer Assisted Learning, 34(1), 6370.

Fidan, M. (2018). Okullarda örgütsel yaratıcılık ve yönetsel inovasyona ilişkin öğretmen görüşlerinin incelenmesi. Hacettepe Üniversitesi, Eğitim Bilimleri Enstitüsü, Ankara

Fidan, M. (2020a). Mutlu Okulun Bileşenleri. Eğitim ve Toplum Araştırmaları Dergisi, 7(1), 107-123.

Fidan, M. (2020b). Covid-19 belirsizliğinde eğitim: İlkokulda zorunlu uzaktan eğitime ilişkin öğretmen görüşleri. Uşak Üniversitesi Eğitim Araştırmaları Dergisi, 6(2), 24-43.

Garbe, A., Ogurlu, U., Logan, N., \& Cook, P. (2020). Parents' experiences with remote education during covid-19 school closures. American Journal of Qualitative Research, 4(3), 45-65.

Gassman-Pines, A., Ananat, E. O., \& Fitz-Henley, J. (2020). COVID-19 and parent-child psychological well-being. Pediatrics, 146(4), 1-11.

Giorgi, A. (1997). The theory, practice, and evaluation of the phenomenological method as a qualitative research procedure. Journal of phenomenological psychology, 28(2), 235260.

Griffin, J. (2007). What do happiness studies study?. Journal of Happiness Studies, 8(1), 139148. 
Hebebci, M. T., Bertiz, Y., \& Alan, S. (2020). Investigation of views of students and teachers on distance education practices during the Coronavirus (COVID-19) Pandemic. International Journal of Technology in Education and Science (IJTES), 4(4), 267-282.

Hodges, C., Moore, S., Lockee, B., Trust, T., \& Bond, A. (2020). The difference between emergency remote teaching and online learning. Educause Review, 27, 1-12.

Iivari, N., Sharma, S., \& Ventä-Olkkonen, L. (2020). Digital transformation of everyday lifeHow COVID-19 pandemic transformed the basic education of the young generation and why information management research should care? International Journal of Information Management, 55, 102183.

Jacobsen, B. (2007). What is happiness? The concept of happiness in existential psychology and therapy. Existential Analysis, 18(1), 39-53.

Keeling, C., \& Haugestad, A. (2020). Digital Student Preferences: a study of blended learning in Norwegian higher education. Nordic Journal of Modern Language Methodology, 8(2), 89-112.

Keller, F. S. (1968). Good-bye, teacher... Journal of Applied Behavior Analysis, 1(1), 79-98.

Keskin, M., \& Kaya, D. Ö. (2020). COVID-19 sürecinde öğrencilerin web tabanlı uzaktan eğitime yönelik geri bildirimlerinin değerlendirilmesi. İzmir Katip Çelebi Üniversitesi Sağlık Bilimleri Fakültesi Dergisi, 5(2), 59-67.

Langlois, S., Xyrichis, A., Daulton, B. J., Gilbert, J., Lackie, K., Lising, D., ... \& Khalili, H. (2020). The COVID-19 crisis silver lining: interprofessional education to guide future innovation. Journal of Interprofessional Care, 34(5), 587-592.

Lie, A., Tamah, S. M., Gozali, I., Triwidayati, K. R., Utami, T. S. D., \& Jemadi, F. (2020). Secondary school language teachers' online learning engagement during the COVID-19 pandemic in Indonesia. Journal of Information Technology Education: Research, 19, 803-832.

Louise Barriball, K. \& While, A. (1994). Collecting Data using a semi-structured interview: a discussion paper. Journal of Advanced Nursing, 19(2), 328-335.

Moore, M. G., \& Kearsley, G. G. (1996). Distance Education: A System View. Wadsworth.

Moustakas, E. (1994). Phenomenological research methods. Thousand Oaks, CA: Sage. 
Patrick, S. W., Henkhaus, L. E., Zickafoose, J. S., Lovell, K., Halvorson, A., Loch, S., ... \& Davis, M. M. (2020). Well-being of parents and children during the COVID-19 $\begin{array}{llll}\text { pandemic: } & \text { a } & \text { national }\end{array}$ https://doi.org/10.1542/peds.2020-016824

Rahman, A., Brodie-McKenzie, A., Gillett, W., Holdsworth, R., Heggart, K., Smith, D., ... \& Coutts, N. (2020). Reflection: On-line, blended and face-to-face learning: Harnessing flexibility and freedom' reflections on remote learning during the COVID-19 pandemic'. Connect, (243), 23-32.

Roblyer, M. D. \& Doering, A. H. (2006). Integrating Educational Technology into Teaching (Vol. 2). Upper Saddle River, NJ: Pearson/Merrill Prentice Hall.

Rose S. (2020). Medical student education in the time of COVID19. JAMA. 323(21), 21312132.

Sculi, J., Phillips, M., Sharma, U. \& Garnier, K. (2020). Innovations in teacher education at the time of COVID19: an Australian perspective. Journal of Education for Teaching, 46(4), $1-10$.

Sharifi, A., \& Khavarian-Garmsir, A. R. (2020). The COVID-19 pandemic: Impacts on cities and major lessons for urban planning, design, and management. Science of The Total Environment, 749, 1-14. https://doi.org/10.1016/j.scitotenv.2020.142391

Shearer, R. L., Aldemir, T., Hitchcock, J., Resig, J., Driver, J., \& Kohler, M. (2020). What students want: A vision of a future online learning experience grounded in distance education theory. American Journal of Distance Education, 34(1), 36-52.

Sokal, L., Trudel, L. E., \& Babb, J. (2020). Canadian teachers' attitudes toward change, efficacy, and burnout during the COVID-19 pandemic. International Journal of Educational Research Open, 1, 1-8. https://doi.org/10.1016/j.ijedro.2020.100016

Suryaman, M., Cahyono, Y., Muliansyah, D., Bustani, O., Suryani, P., Fahlevi, M., ... \& Munthe, A. P. (2020). COVID-19 pandemic and home online learning system: Does it affect the quality of pharmacy school learning? Systematic Reviews in Pharmacy, 11(8), 524-530.

Susilowati, E. \& Azzasyofia, M. (2020). The parents stress level in facing children study from home in the early of Covid-19 pandemic in Indonesia. International Journal of Science and Society, 2(3), 1-12. 
Telli Yamamoto, S. G. \& Altun, D. (2020). Coronavirüs ve çevrimiçi (online) eğitimin önlenemeyen yükselişi. Üniversite Araştırmaları Dergisi, 3(1), 25-34.

Trout, B. S. (2020). The coronavirus-induced transition to online learning: Perceptions and intentions of first-time online students. Quarterly Review of Distance Education, 21(1). $1-12$.

Ünüvar, P., Calışandemir, F., Tagay, O., Amini, F. (2015). Preschool children's perception of happiness (Turkey and Afghanistan sample). Mehmet Akif Ersoy Üniversitesi Eğitim Fakültesi Dergisi, 15(34), 1-22.

Veenhoven, R. (2005). Is life getting better? How long and happily do people live in modern society? European psychologist, 10(4), 330-343.

Volery, T. \& Lord, D. (2000), Critical success factors in online education, International Journal of Educational Management, 14(5). 216-223.

Yıldırım, A. \& Şimşek, H. (2003). Sosyal Bilimlerde Nitel Araştırma Yöntemleri (8.baskı). Ankara: Seçkin. 


\section{Yazarlar Hakkında}

\section{Mustafa FIDAN}

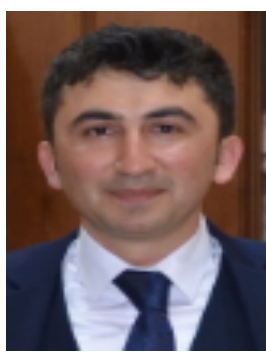

Mustafa Fidan, Atatürk Üniversitesi Eğitim Fakültesi Sınıf Öğretmenliği lisans mezunudur. Lisansüstü eğitimine Eğitim Yönetimi alanında devam eden yazar, Atatürk Üniversitesi Eğitim Fakültesinde yüksek lisans ve Hacettepe Üniversitesi Eğitim Fakültesinde doktora eğitimi almıştır. 2017 yılından bugüne Ankara Özel Acar Okulları İlkokul kademesinde sınıf öğretmeni olarak görev yapmaktadır. Yazarın çalışma alanları, eğitim bilimleri, sınıf yönetimi, inovasyon, öz-liderlik, mutluluk, mutlu okul, iletişim ve yaratıcılık konularıdır.

Posta adresi:

Tel (İş):

GSM:

Turgut Özal Mahallesi, 1940. Cadde No:5/A-B, 06370 Yenimahalle/ANKARA

Eposta: +9003125664566 +905366461402

URL: gfidanmustafa@gmail.com http://dergipark.org.tr/tr/pub/@fidanmustafa 